\title{
Cinacalcet for Hypercalcemia Caused by Pulmonary Squamous Cell Carcinoma Producing Parathyroid Hormone-Related Peptide
}

\author{
Anneke Bech $^{\mathrm{a}}$ Koen Smolders $^{\mathrm{b}}$ Darryl Telting $^{\mathrm{c}}$ \\ Hans de Boer ${ }^{\text {a }}$ \\ Departments of ${ }^{\mathrm{a}}$ Internal Medicine, ${ }^{\mathrm{b}} \mathrm{Pulmonary}$ Medicine, and ${ }^{\mathrm{c}} \mathrm{Clinical}$ \\ Chemistry, Rijnstate Hospital, Arnhem, The Netherlands
}

\section{Key Words}

Lung cell carcinoma $\cdot$ Hypercalcemia Parathyroid hormone-related peptide ·

Cinacalcet

\section{Abstract}

Background: Current treatments for hypercalcemia caused by lung cell carcinomas producing parathyroid hormone-related peptide (PTH-rp) have limited efficacy, probably because of their lack of effect on PTH-rp secretion. In this case study we explored the efficacy of the calcimimetic cinacalcet as suppressor of PTH-rp production.

Patient: A 57-year-old male with severe and recurrent hypercalcemia induced by a PTH-rpproducing squamous cell lung carcinoma, stage $C T 4 N 3 M 1 b$, poorly responding to standard treatments.

Results: Serum PTH-rp levels were not affected by saline, calcitonin or zoledronate. PTH-rp decreased during chemotherapy and cinacalcet monotherapy. The combination of chemotherapy plus cinacalcet was most effective in rapidly reducing serum calcium and PTHrp.

Conclusion: This case study is the first to suggest that cinacalcet may be of value in some cases of PTH-rp-dependent hypercalcemia. Corroborative evidence is needed.

\section{Introduction}

Humoral hypercalcemia of malignancy (HHM) is the most common paraneoplastic syndrome in cancer patients. In $80 \%$ of cases HHM is caused by the production of parathyroid hormone-related peptide (PTH-rp) $[1,2]$. It is most common in squamous

A. Bech, MD 
cell carcinoma of the lung, with a reported incidence of $5-10 \%$, depending on the stage of disease $[3,4]$.

PTH and PTH-rp both target the PTH receptors in bone and kidney in a similar way. They simultaneously stimulate osteoclastic bone resorption, increase renal calcium reabsorption and promote the formation of 1,25-dihydroxyvitamin D [5]. Due to this combination of actions on calcium absorption, mobilization and excretion, PTH-rpproducing carcinomas can cause a rapid and excessive rise in serum calcium that is often resistant to conventional treatment with forced hydration and intravenous bisphosphonates, because these interventions do not block all effects of PTH-rp. Moreover, the effects of bisphosphonates on bone resorption are usually short-lived, because PTH-rp levels are not affected and the stimulus for enhanced bone resorption is maintained. The efficacy of bisphosphonates is inversely related to serum PTH-rp [6]. In view of these findings it is conceivable that suppression of PTH-rp secretion or blockade of PTH-rp activity could be beneficial. We hypothesized that it might help to reduce serum calcium, as well as to reduce tumor progression. The latter is suggested by observations that PTH-rp promotes spreading of bone metastasis and can act as an autocrine growth factor inhibiting lung cancer cell apoptosis [7].

Present day knowledge of factors affecting cancer cell PTH-rp production is mainly limited to in vitro observations in carcinoma cell lines. These studies have shown that calcitonin, epidermal growth factor, transforming growth factor beta, insulin and cycloheximide increase PTH-rp transcription [8-11], that cAMP promotes the release of PTH-rp [12], and that 1,25-OH vitamin D agonists and IL-4 can suppress PTH-rp gene expression $[8,10,11]$. There is also evidence that the calcium-sensing receptor $(\mathrm{CaR})$ is important for the regulation of PTH-rp secretion in normal as well as in malignant cells [13]. Normal cell lines producing PTH-rp respond to CaR activation with a decrease in PTH-rp secretion, whereas some cancer cell lines may respond with an increase in PTHrp release [13-15]. This reversal in response has been shown in some breast, prostate, and testicular cancer cell lines, a phenomenon that has been attributed to a switch in the type of G-protein that is activated by the CaR [14-16]. Reversal in response is not a universal characteristic of cancer cells. A human small cell lung carcinoma cell line expressing the $\mathrm{CaR}$ and producing PTH-rp, responded like normal cells, i.e. increasing the $\mathrm{Ca}^{2+}$ concentration in the growth medium reduced PTH-rp secretion, whereas a decrease in $\mathrm{Ca}^{2+}$ was associated with an increase in PTH-rp release [15]. The type of response to $\mathrm{CaR}$ activation of squamous cell lung carcinomas is currently not known.

When a patient presented with severe and treatment-resistant hypercalcemia caused by a PTH-rp producing lung carcinoma, we considered that the calcimimetic cinacalcet might be a reasonable candidate compound to achieve PTH-rp suppression. We hypothesized that if this tumor expressed CaRs, PTH-rp production might be suppressible with cinacalcet, and that this could have a beneficial effect on serum calcium and possibly on survival as well. Animal studies support that line of thought. Animals treated with humanized anti-PTH-rp antibodies showed a resolution of hypercalcemia, inhibition of bone metastases and disappearance of cachexia [5, 17]. 


\section{Materials and Methods}

Serum intact PTH (normal range: $1.3-6.8 \mathrm{pmol} / \mathrm{l}$ ) was measured by a solid-phase, two-site chemiluminescent enzyme-labeled immunometric assay (Immulite 2500, Siemens, Los Angeles, Calif., USA), with an intra- and interassay precision of $<6$ and $<9 \%$, respectively. PTH-rp (normal range: $<0.6$ pmol/l) was measured by an immunoradiometric assay (Immunotech, Prague, Czech Republic), with an intra- and interassay precision of $<8.9$ and $<10 \%$, respectively. All other laboratory parameters were measured by routine clinical chemistry assays (Roche Diagnostics, Almere, The Netherlands). The serum calcium (Ca) levels referred to in the text and in the figures represent total calcium levels corrected for albumin according to the equation: $\mathrm{Ca}$ in $\mathrm{mmol} / \mathrm{l}=$ total calcium $-(0.025 \times$ albumin in $\mathrm{g} / \mathrm{l})+1$. Serum ionized calcium $\left(\mathrm{Ca}^{2+}\right)$ was measured with a blood gas analyzer (OMNI Roche, Mannheim, Germany).

Case

A 57-year-old man presented with recent onset weakness, severe constipation and $5 \mathrm{~kg}$ weight loss. Physical examination was unremarkable but laboratory investigation revealed renal failure, severe hypercalcemia, and an elevated PTH-rp: serum creatinine $214 \mu \mathrm{mol} / \mathrm{l}$, Ca $4.56 \mathrm{mmol} / \mathrm{l}$, phosphate $0.91 \mathrm{mmol} / \mathrm{l}, \mathrm{PTH}<1 \mathrm{pmol} / \mathrm{l}$, and PTH-rp $5.8 \mathrm{pmol} / \mathrm{l}$. Additional investigations led to a diagnosis of squamous cell carcinoma of the lung, stage cT4N3M1b, with metastases in bone and liver. Intravenous fluid replacement $(\mathrm{NaCl} 0.9 \%, 4 \mathrm{l} / 24 \mathrm{~h})$, combined with calcitonin $450 \mathrm{IU}$ subcutaneously twice a day for 5 days, and pamidronate $90 \mathrm{mg}$ intravenously in week 1 and 2 reduced serum Ca to $2.84 \mathrm{mmol} / \mathrm{l}$ (data not shown). A fortnight later serum Ca had increased again to $4.40 \mathrm{mmol} / \mathrm{l}$. Fluid replacement was started again (fig. 1, blue bar), now in combination with calcitonin 250 IU twice a day subcutaneously for 5 days (salmon bar) and a single dose of zoledronate $5 \mathrm{mg}$ intravenously (purple dot). These 5 days of combination treatment reduced serum Ca to $3.20 \mathrm{mmol} / \mathrm{l}$, but there was no effect on serum PTH-rp levels. On the 6th day serum Ca rose again to $3.50 \mathrm{mmol} / \mathrm{l}$, and after obtaining informed consent, cinacalcet was started, $30 \mathrm{mg}$ twice a day, and continued for a period of 15 days (green bar). Chemotherapy, consisting of cycles of carboplatin and gemcitabine, was started two days later (black asterisks). During combined chemotherapy and cinacalcet treatment, serum PTH-rp decreased rapidly, and this was finally associated with a fall in serum Ca into the hypocalcemic range (ionized calcium $0.86 \mathrm{mmol} / \mathrm{l}$ ). Cinacalcet was discontinued, and the next day a prompt rise in serum PTH was observed, from an undetectable level to a concentration of $5.1 \mathrm{pmol} / \mathrm{l}$, associated with a normalization of serum Ca. Subsequently, the patient received three cycles of chemotherapy. Each cycle was preceded by a gradual rise in serum PTH-rp and serum Ca, and followed by a decrease in both parameters. Only the first cycle of chemotherapy had been given in combination with cinacalcet. During this first cycle serum PTH-rp decreased from 13.2 to 0.9 pmol/l in 15 days. During the 2nd, 3rd, and 4th chemotherapy cycles the decreases in PTH-rp were much smaller and slower than during the 1st cycle. Just before the 4 th cycle serum Ca had increased to 3.71 $\mathrm{mmol} / \mathrm{l}$ and forced hydration and chemotherapy was required to normalize the serum Ca level again. Chemotherapy resulted in stable disease according to RECIST-criteria, but soon after the 4th cycle serum Ca rose again to about $3.50 \mathrm{mmol} / \mathrm{l}$. Hydration and cinacalcet was started in a dose of $60 \mathrm{mg}$ twice daily. Although PTH-rp decreased from 8.7 to $5.0 \mathrm{pmol} / \mathrm{l}$, this alone did not immediately affect serum Ca levels. Calcium levels stabilized around 3.50-3.80 mmol/l. Only when a 5-mg dose of zoledronate was given in addition, serum Ca decreased to a value below $3.00 \mathrm{mmol} / \mathrm{l}$, and the patient could be discharged on cinacalcet $60 \mathrm{mg}$ twice a day. Unfortunately, the Ca-lowering effect was shortlived, and 9 days later hospitalization was necessary again and another dose of zoledronate was given. When the patient was informed that the chest X-ray showed progression of the tumor, he declined further treatment and was discharged on request. Two weeks later he died at home.

To examine the importance of PTH-rp as determinant of serum Ca levels in this patient, ionized serum calcium was plotted as a function of serum PTH-rp (fig. 2 ). Despite the many different interventions to reduce serum $\mathrm{Ca}^{2+}$, there was a strong correlation between the two variables. PTH-rp levels explained $71 \%$ of the variance in serum $\mathrm{Ca}^{2+}$ 


\section{Discussion}

To our knowledge, this is the first case where cinacalcet was used to treat PTH-rprelated hypercalcemia. It is not easy to assess without doubt which factors contributed significantly to the changes in serum PTH-rp and Ca because the analysis is hampered by the simultaneous use of different types of treatments during various periods,. Although recognizing that the evidence is not conclusive, we believe that several observations support the conclusion that cinacalcet by itself did have PTH-rpsuppressive effects, and that further evaluation of this use of cinacalcet in a larger setting is warranted.

During the first five days, when a combination of saline, calcitonin and zoledronate was given, serum PTH-rp did not change, and it was concluded that none of these agents had an effect on PTH-rp secretion. During the next two weeks the patient was treated with cinacalcet 30 twice daily in combination with chemotherapy. In this period a major decline in serum PTH-rp occurred. Thus, one or both factors must have reduced PTH-rp secretion. Tumor load reduction by chemotherapy is likely to have contributed to the decrease in PTH-rp levels, and this is supported by the declines in PTH-rp that occurred during each of the next cycles of chemotherapy not combined with other treatment. Two observations are likely to suggest that cinacalcet has also exerted PTHrp lowering effects. First, the decline in PTH-rp during the first cycle of chemotherapy was much steeper than during the next three cycles when no cinacalcet was given. Second, when hypercalcemia recurred after the fourth cycle of chemotherapy, cinacalcet monotherapy induced a consistent decline in serum PTH-rp and prevented a further rise in serum Ca. The observation that serum Ca did not normalize during this period does not dispute the effect of cinacalcet on PTH-rp secretion. It merely indicates that osteoclast activation still continued at a certain level because PTH-rp suppression was not complete. Additional bisphosphonate treatment was needed to further reduce the Ca efflux from bone.

Figure 2 illustrates the importance of PTH-rp reduction in HHM and shows that $71 \%$

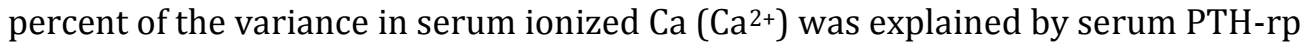
levels. The relationship was very strong for serum $\mathrm{Ca}^{2+}$ levels up to $1.75 \mathrm{mmol} / \mathrm{l}$ and then weakened substantially. The latter is attributed to the confounding effects of the various treatments that were started when serum $\mathrm{Ca}^{2+}$ was in this high range. These treatments disturbed the relationship between PTH-rp and serum $\mathrm{Ca}^{2+}$ considerably because they affected serum $\mathrm{Ca}^{2+}$ without altering serum PTH-rp.

The present case also illustrates that the use of cinacalcet in PTH-rp-dependent hypercalcemia may not be without risk and should be closely monitored. During the first treatment period serum Ca dropped into the hypocalcemic range. This did not occur when chemotherapy was given alone, and thus this effect must be related to the use of cinacalcet. The hypocalcemic episode is attributed to cinacalcet's suppression of the parathyroid glands. As shown in figure 1, PTH increased rapidly when cinacalcet was discontinued, and this restored serum calcium within a few days.

It is also important to note that the response to cinacalcet may vary from case to case. It is likely to depend on the degree of CaR expression and the presence of a normal post-receptor signaling pathway. The response to cinacalcet may also vary among the various types of malignancies, and maybe even among patients with similar 
types of cancer. In vitro studies have shown that breast and prostate cancer cell lines may respond to $\mathrm{CaR}$ agonists by increasing PTH-rp secretion, thus creating a vicious cycle [13]. It is currently not known whether this reversal in CaR responsiveness, an observation made in cell cultures only, can also occur in vivo. In the present case, PTHrp levels decreased on both occasions where cinacalcet was used, indicating that $\mathrm{CaR}$ responsiveness was not reversed.

At present, it is not known for how long cinacalcet may exert PTH-rp-suppressive effects in cancer cells. In the final weeks of his life the patient's serum PTH-rp levels increased rapidly, despite the prescription of cinacalcet. As we didn't measure cinacalcet serum levels we do not know whether there was reduced patient compliance, loss of cinacalcet's suppressive action or rapid tumor progression.

It is concluded that reduction of PTH-rp is an important target to reduce serum Ca in HHM. It can be achieved by tumor mass reduction by surgery, chemotherapy or radiotherapy. Although the evidence is not conclusive, the present case at least suggests that PTH-rp production can be reduced by the use of cinacalcet. It is well recognized that confirmation is needed and that many aspects require further evaluation. For example, it is currently not known how often PTH-rp-producing lung carcinomas express the $\mathrm{CaR}$, what percentage responds to cinacalcet with a decrease in PTH-rp, whether cinacalcet-mediated PTH-rp suppression affects survival in lung cancer patients, and whether cinacalcet may be effective in other types of PTH-rp-producing cancers.

\section{Disclosure Statement}

None of the authors have any conflict of interest to report. This research did not receive any specific grant from any funding agency in the public, commercial or not-for-profit sector. 


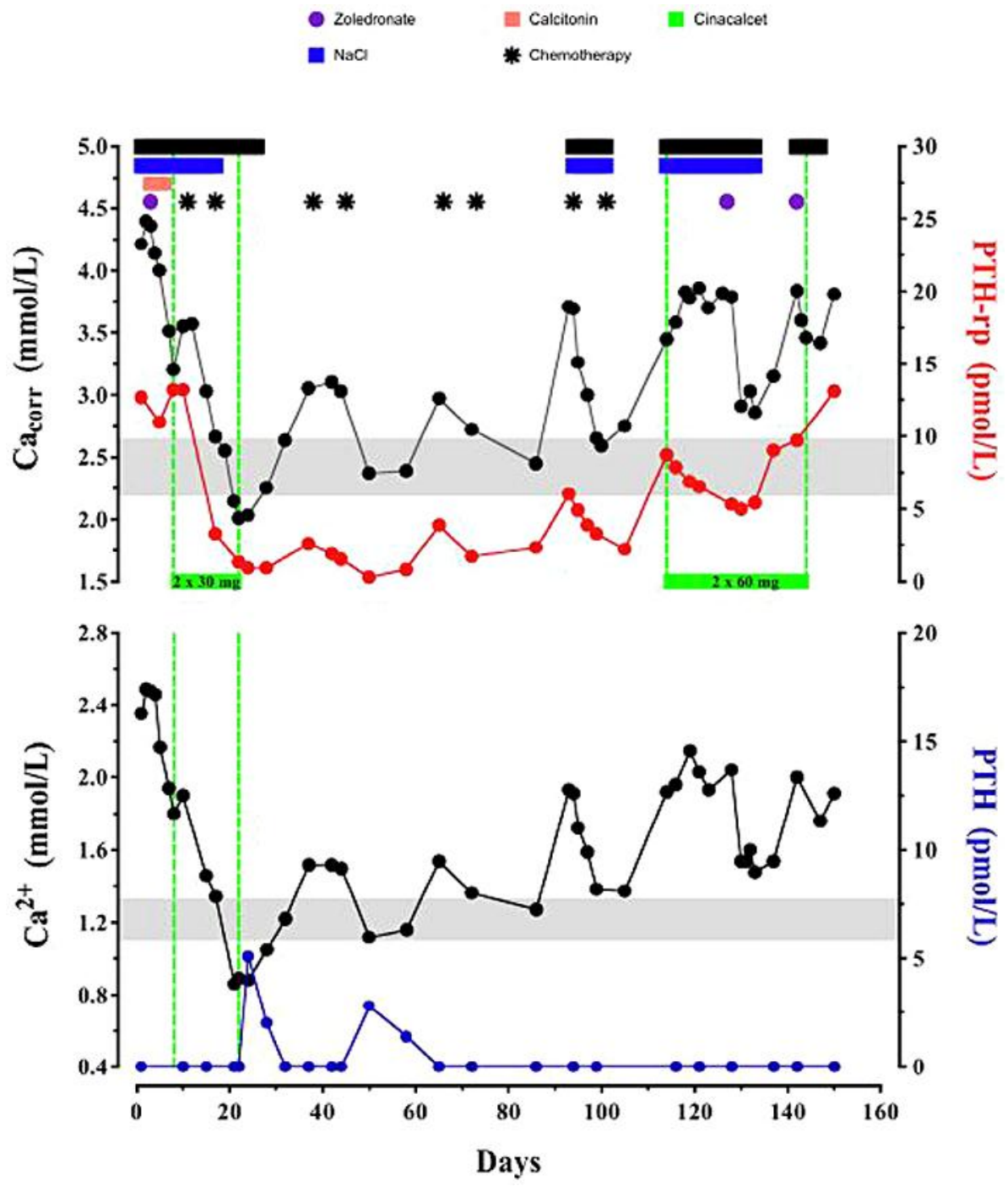

Fig. 1. Calcium and PTH-rp responses to various treatments. Black bar: in-hospital stay, blue bar: $\mathrm{NaCl}$ 0.9\% intravenously, salmon bar: calcitonin subcutaneously twice a day, purple dot: single dose of zoledronate $5 \mathrm{mg}$ intravenously, black asterisk: chemotherapy, green bar: cinacalcet treatment. 


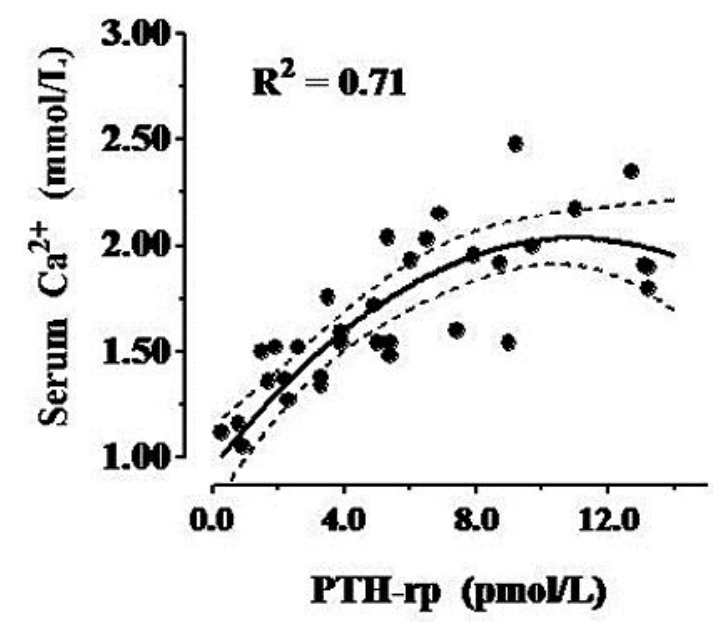

Fig. 2. PTH-rp as determinant of serum ionized calcium concentration.

\section{References}

1 Mosely JM, Kubota M, Diefenbach-Jagger H, et al: Parathyroid hormone-related protein purified from a human lung cancer cell line. Proc Natl Acad Sci USA 1987;4:5048-5052.

$\checkmark 2$ Burtis WJ, Brady TG, Orloff JJ, et al: Immunochemical characterization of circulating parathyroid hormone-related protein in patients with human hypercalcemia of cancer. N Engl J Med 1990;322:11061112.

3 Takai E, Yano T, Iguchi H, et al: Tumor-induced hypercalcemia and parathyroid hormone-related protein in lung carcinoma. Cancer 1996;78:1384-1387.

4 Hiraki A, Ueoka H, Bessho A, et al: Parathyroid hormone-related protein measured at the time of first visit is an indicator of bone metastases and survival in lung carcinoma patients with hypercalcemia. Cancer 2002;95:1706-1713.

5 Sato K, Onuma E, Yocrum RC, et al: Treatment of malignancy-associated hypercalcemia and cachexica with humanized anti-parathyroid hormone-related protein antibody. Semin Oncol 2003;30:167-173.

-6 Onuma E, Azuma Y, Saito H, et al: Increased renal calcium reabsorption by parathyroid hormone-related protein is a causative factor in the development of humoral hypercalcemia of malignancy refractory to osteoclastic bone resorption inhibitors. Clin Cancer Res 2005;11:4198-4203.

7 Hastings RH, Araiza F, Burton D, et al: Parathyroid hormone-related protein regulates apoptosis in lung cancer cells through protein kinase A. Am J Physiol Cell Physiol 2004;287:1616-1622.

8 Chilco PJ, Leopold V, Zajaz JD: Differential regulation of the parathyroid hormone-related protein gene P1 and P3 promoters by cAMP. Mol Cell Endocrinol 1998;138:173-184.

-9 Lorch G, Gilmore JL, Koltz PF, et al: Inhibition of epidermal growth factor receptor signaling reduces hypercalcaemia induces by human lung squamous-cell carcinoma in athymic mice. Br J Cancer 2007;97:183-193.

10 Falzon M, Zong J: The noncalcemic vitamin D analogs EB1089 and 22-oxacalcitriol suppress seruminduced parathyroid hormone-related peptide gene expression in a lung cancer cell line. Endocrinology 1998;139:1046-1053.

11 Nagasaki K, Yamaguchi K, Watanabe K, et al: Interleukin-4 blocks parathyroid hormone-related proteininduced hypercalcemia in vivo. Biochem Biophys Res Commun 1991;178:694-698.

12 Rizolli R, Aubert ML, Sappino AP, et al: Cyclic AMP increases the release of parathyroid hormone-related protein from a lung-cancer cell line. Int J Cancer 1994;56:422-426.

13 Saidak Z, Mentaverri R, Brown EM: The role of the calcium-sensing receptor in the development and progression of cancer. Endocr Rev 2009;30:178-195. 
14 Mamillapalli R, van Houten J, Zawalich W, Wyolmerski J: Switching of G-protein usage by the calciumsensing receptor reverses its effect on parathyroid hormone-related protein secretion in normal versus malignant breast cells. J Biol Chem 2008;283:24435-24447.

15 Ishikawa M, Kimura K, Tachibana T, et al: Establishment and characterization of a novel cell line derived from a human small cell lung carcinoma that secretes parathyroid hormone, parathyroid hormonerelated protein, and pro-opiomelanocortin. Human Cell 2010;23:58-64.

16 Chakravarti B, Dwivedi SK, Mithal A, Chattopadhyay N: Calcium-sensing receptor in cancer: good cop or bad cop? Endocrine 2009;35:271-284.

17 Miki T, Yano S, Hanibuchi M, et al: Parathyroid hormone-related protein is responsible for production of bone metastasis, but not visceral metastasis, by human small celllung cancer SBC - 5 ells in natural killer cell-depleted SCID mice. Int J Cancer 2004;108:511-515. 